\title{
Pelatihan Desain Grafis Photoshop dan Coreldraw di Korem 071 Wijayakusuma guna meningkatkan Kemampuan Desain Grafis bagi para Anggota TNI
}

\author{
Bita Parga Zen ${ }^{1)} \mid$ Muhamad Azrino Gustalika ${ }^{2)}$ \\ 1,2 Institut Teknologi Telkom Purwokerto \\ bita@ittelkom-pwt.ac.id | azrino@ittelkom-pwt.ac.id
}

\begin{abstract}
Abstrak: Seiring perkembangan teknologi dan informasi, banyak hal yang dapat merubah kehidupan masyarakat melalui teknologi. Hal ini terjadi dikarenakan setiap manusia harus memiliki keahlian sesuai dengan kemajuan zaman. Institut Teknologi Telkom Purwokerto memfasilitasi hal itu melalui tridarma perguruan tinggi yakni dosen melakukan pengabdian kepada masyarakat agar masyarakat bisa memperoleh kemampuan yang di butuhkan saat ini. Melalui pengabdian masyarakat di harapakan memapu menjembantani antara pihak yang akan melakukan pelatihan dengan pihak kampus yakni Institut Teknologi Telkom Purwokerto. Institut Telkom Purwokerto bekerja sama dengan Korem 071 Wijayakusuma dalam hal peningkatan kualitas terhadap peserta pelatihan dengan menggunakan pelatihan desain grafis. Pelatihan ini di ikuti sebanyak 31 peserta dari anggota dan keluarga Korem 071 Wijayakusuma. Oleh karena itu pelatihan ini sangat di butuhkan agar para peserta bisa mengembangkan dan menerapkan hasil dari pelatihan ini ke bidang industri seperti membuka usaha sendiri. Sebelumnya para peserta kurang dalam memahami dan mengetahui manfaat dari pelatihan desain grafis untuk kehidupan mereka. Oleh karena itu Institut Teknologi Telkom Purwokerto meyiapkan pemateri yang handal dalam memberika pelatihan desain grafis agar para peserta bisa memanfatkannya dengan baik. Pelatihan desain grafis ini di laksanalan selama dua hari di laboratorium milik Institut Teknologi Telkom Purwokerto dimana hari pertama peserta akan di beri pelatihan berupa pembuatan logo dan poster dengan menggunakan aplikasi Coreldraw dan hari kedua pembuatan banner dan desain web menggunakan apliaksi Photoshop. Dalam hal ini peserta sangat antusias dengan di adakannya pelatihan desain grafis dengan di tandai dengan kuisoner kepuasan peserta pelatihan dimana rata-rata dari mereka merasa sangat setuju atau puas terhadap pelatihan ini, sehingga di harapkan adanya pelatihan yang berkelanjutan.
\end{abstract}

Kata Kunci: Desain Grafis; Korem 071 Wijayakusuma; CorelDraw; Photoshop

\section{Pendahuluan}

Seiring dengan kemajuan teknologi dan informasi banyak hal yang dapat mengubah kehidupan masyarakat melalui teknologi. Fenomena perubahan tersebut terjadi dikarenakan setiap individu harus dapat beradaptasi dan berkembang agar dapat mengikuti perkembangan jaman, setiap individu harus memiliki keahlian dengan kebutuhan zaman (Jepriana, Ferdi, \& Putra, 2020). Sivitas Akademika Institut Teknologi Telkom Purwokerto memiliki tanggung jawab dalam menjalankan Tridarma Perguruan Tinggi, di mana hal tersebut tertuang di Undang undang No 12 Tahun 2012 Pasal 1 Ayat 9 dijelaskan bahwa kewajiban perguruan tinggi untuk menyelenggarakan Pendidikan, Penelitian dan Pengabdian Masyarakat, dalam hal ini yaitu melakukan pengabdian masyarakat ke Anggota dan Keluarga dari Korem 071 Wijayakusuma Kabupaten Banyumas berupa pelatihan desain grafis menggunakan CorelDraw dan Photoshop. Kelahiran Korem 071/wijayakusuma sendiri tidak dapat 
Dedikasi Sains dan Teknologi

Jurnal Pengabdian Masyarakat

Vol: 1, No: 1, Mei 2021

Doi : https://doi.org/10.47709/dst.v1i1.952
Submitted : 30 April 2021

Accepted : 5 Mei 2021

Published : 8 Mei 2021

terlepas dari semangat dan jiwa pada Proklamasi Kemerdekaan Republik Indonesia. Panitia Persiapan Keerdekaan Indoneisa mengeluarkan pengumuman pada tanggal 23 Agustus 1945 dan di bentuknya Badan Keamanan Rakyat pada tanggal 30 Agustus 1945 yang terletak di daerah Banyumas dan di pimpin oleh Bapak Soedirman, Bapak Gatot Soebroto dan Bapak Sutirto, Sementara untuk Bapak Rochim Gondosuwito dan Bapak Iskandar Idris merupakan eks keresidenan Pekalongan dalam memimpin Badan Keamanan Rakyat. Selanjutnya pada tanggal 5 Oktober1945 dibentuk 16 Divisi Tentara Keamanan Rakyat (korem071.mil.id, 2019). Manusia membutuhkan yang namanya proses komunikasi. Proses komunikasi yang menggunakan elemen visual dalam bentuk tulisan, gambar dan bentuk untuk menciptakan suatu pesan yang ingin di sampaikan bernama desain grafis(Andriyanto1, 2021). Desain grafis disebut juga sebagai aplikasi dari ketrampilan seni dan komunikasi untuk kebutuhan bisnis dan industri(Sipayung, 2020). Hal inilah yang mendasari diadakannya pelatihan untuk anggota dan keluarga korem 071 Wijayakusuma. Anggota korem 071 Wijayakusuma masih belum memahami dan mengerti mengenai desain grafis yang tentunya berpotensi menghasilkan bisnis bagi mereka sendiri. Kegiatan pelatihan ini sangat penting karena bermanfaat menambah pengetahuan dan ketrampilan bagi yang ingin membuka bisnis dengan desain grafis sebagai dasarnya. Dengan mempelajari Desain grafis lewat pelatihan peningkatan bidang pendidikan dan pelatihan keterampilan bagi anggota korem 071 kusumawijaya diharapkan ada bekal individu yang didapatkan, serta kesiapan peserta dalam terjun langsung kedunia kerja ataupun bisnis(Alkodri, 2020). Manfaat desain grafis pada dunia bisnis adalah sangat membatu dalam pembuatan logo, brosur, kartu nama, spanduk, banner, serta desain website yang menarik(Yahya \& Fitriyanto, 2020). Ada banyak software computer untuk desain grafis seperti CorelDraw dan Photoshop. Pada pelatihan desain grafis ini menggunakan aplikasi CorelDraw dan Phothosop. CorelDraw merupakan pengolah vector berupa garis dan bidang yang di olah berdasarkan pengatiran-pengaturan pada angka vector(Agustina, 2017). CorelDraw menawarkan pengalaman desain yang luar biasa untuk grafik, tata letak, ilustrasi dan lainnya. Sementara itu Adobe Photoshop merupakan program pengolah desain grafis yang familier danpaling diminati di kalangan desain grafis. Program ini dapat digunakan dengan mudah karena terdapat tool-tool maupun efek yang menghasilkan berbagai bentuk desain yang inovatif dan ekspresif dengan dilengkapi komposisi warna yang bagus,serta adanya tool untuk membuat objek yang unik dan kreatif.(Yuliati, 2020).

\section{Realisasi Kegiatan}

Pelaksnaan kegiatan pengabdian ini di lakukan di laboratorium yang berada di Institut Teknlogi Telkom Purwokerto yang meliputi pelatihan yang di berikan secara langsung dan pendampingan langsung step by step selama pembuatan desain grafis menggunakan photoshop dan corel. Kegiatan ini dilaksanakan dalam waktu 2 hari dan di hadiri sebanyak 31 peserta dari anggota dan keluarga Korem 071 Wijayakusuma dan dipandu oleh 4 orang pemateri terdiri dari 2 dosen dan 1 mahasiswa di IT Telkom Purwokerto. Pelaksanaan kegiatan ini menggunakan beberapa metode pembelajaran. antara lain;

1. Metode ceramah; digunakan untuk menyampaikan materi yang berupa teori.

2. Metode praktik; digunakan untuk mempraktikan apa yang telah disampaikan.

3. Metode tanya jawab digunakan untuk memberikan kesempatan bagi peserta yang masih belum memahami materi dan sharing sassion Materi pelatihan di sampaikan dalam waktu 300 menit dan dilanjutkan praktik dengan pendampingan pada setiap peserta. Peserta diarahkan untuk membuat objek bentuk dasar, membuat gambar sederhana, poster, dan desain website dengan menggunakan Coreldraw dan Photoshop. Secara garis besar kegiatan ini terbagi dalam 3 tahapan, yaitu: pengenalan tool, pelaksaaan / praktek, dan survey atau kuisoner 


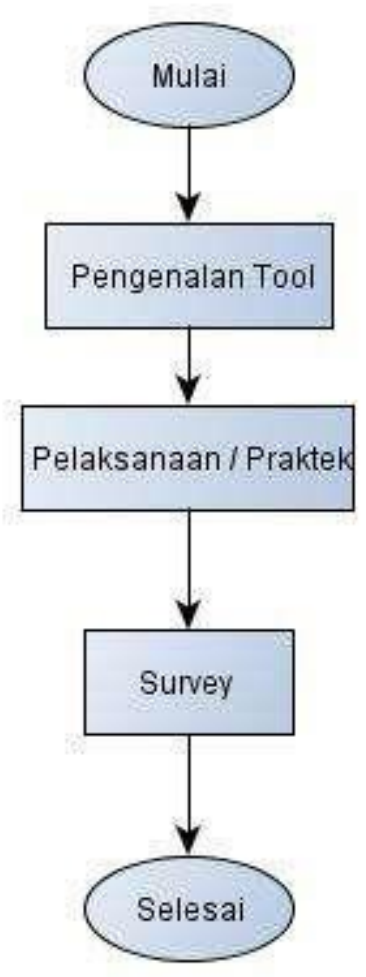

Gambar 1. Diagram alur metode pengabdian

Tahapan pra pelaksaanaa berupa pengenalan tool dari aplikasi Coreldraw dan Aplikasi photoshop. Pemateri menjelaskan kepada peserta mengenai penggunaan dasar aplikasi pelatihan desain grafis. Pada tahapan pelaksanaan di lakukan pelatihan sambil didampingi oleh pemateri dalam mengerjakan pembuatan poster, logo, dan, desain web. Pada tahapan terakhir yaitu tahapa survey. Pemateri memberikan kuisoner kepada peserta yang bertujuan untuk mengetahui kepuasan peserta terhadap pelatihan desain grafis yang telah di berikan.

\section{Hasil}

Kegiatan pengabdian masyarakat ini dilakukan selama 2 hari yang di lakukan pada hari pertama adalah pelatihan pembuatan Logo dan Poster menggunkan aplikasi Software Coreldraw dihari kedua peserta melakukan pelatihan menggunakan software Adobe Photoshop dengan membuat desain berupa website. Untuk lokasi para peserta melakukan pelatihan di laboratorium komputer milik Institut Teknologi Telkom Purwokerto. Di laboratorium tersebut sudah terinstal aplikasi Coreldraw untuk pelatihan peserta anggota dan keluarga korem 071 Wijayakusuma 
Dedikasi Sains dan Teknologi

Jurnal Pengabdian Masyarakat

Vol: 1, No: 1, Mei 2021

Doi : https://doi.org/10.47709/dst.v1i1.952
Submitted : 30 April 2021

Accepted : 5 Mei 2021

Published : 8 Mei 2021
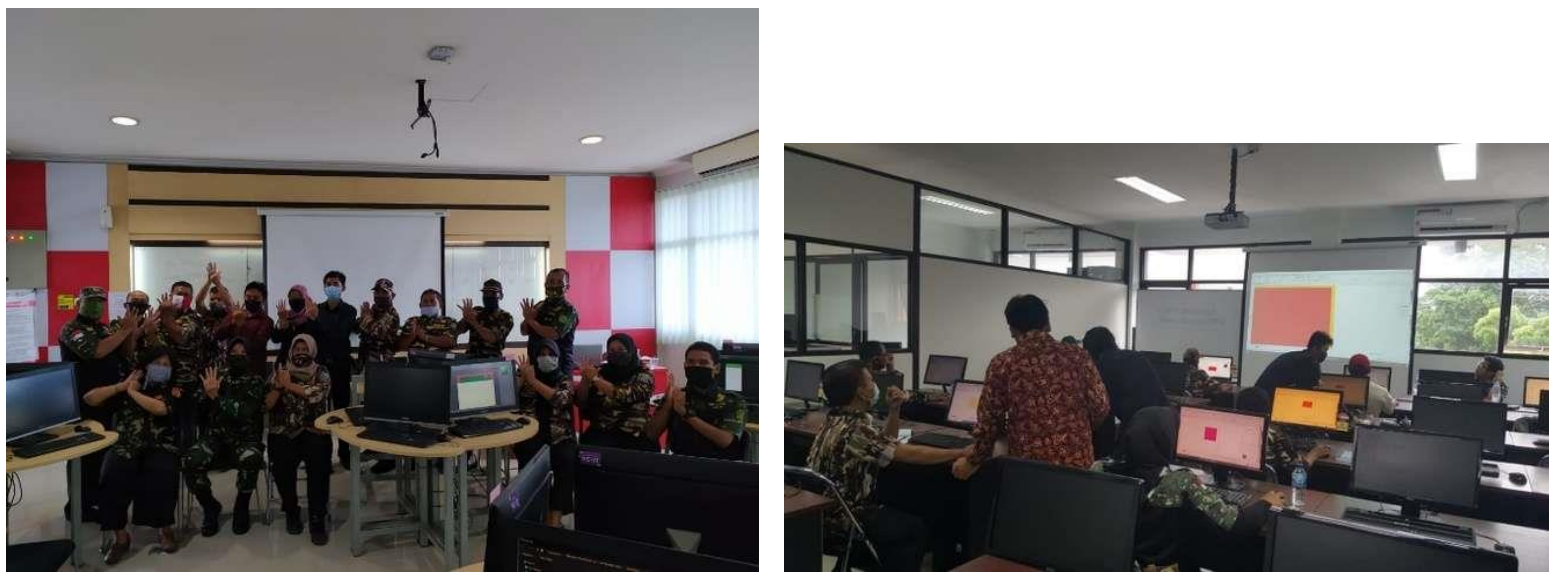

Gambar 2. Pelatihan CorelDraw Hari Pertama

Pada gambar 2, peserta dilatih dengan membuat bermacam desain seperti logo dan poster. Para peserta memiliki kemauan untuk memahami pembuatan logo dan poster sebagai bekal ketrampilan yang cukup mudah untuk di pelajari dan di praktekkan
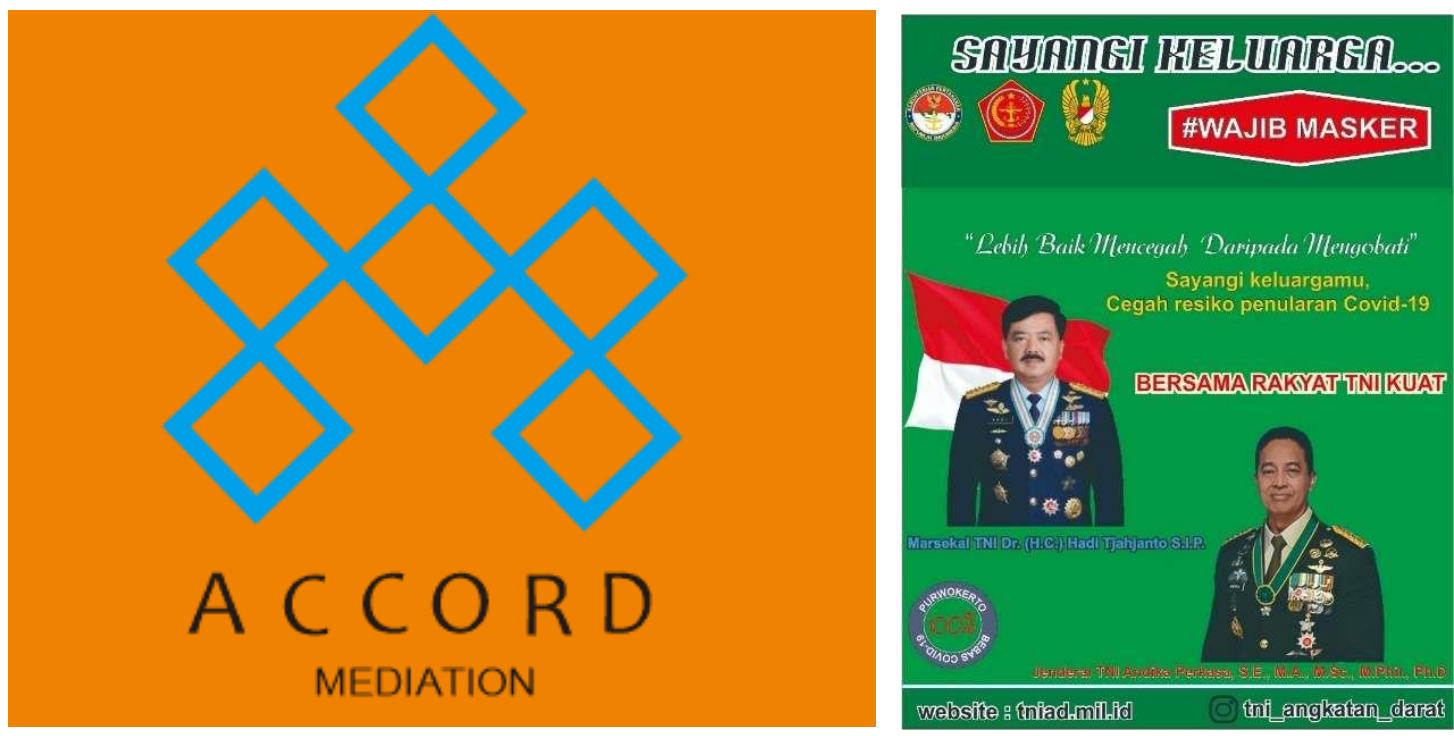

Gambar 3. Hasil desain grafis berupa logo dan poster menggunakan aplikasi Coreldraw

Pada gambar diatas merupakan hasil desain logo dan Poster yang diberikan oleh pemateri lalu diimplementasikan kembali oleh peserta, kemudian pada hari kedua diadakan pelatihan desain grafis adobe photoshop. Pada hari kedua peserta di latih untuk membuat banner dan desain dari sebuah website. Para peserta juga di bekali pengenalan tool dasar penggunaan adobe photoshop oleh pemateri. 
Dedikasi Sains dan Teknologi

Jurnal Pengabdian Masyarakat

Vol: 1, No: 1, Mei 2021

Doi : https://doi.org/10.47709/dst.v1i1.952
Submitted : 30 April 2021

Accepted : 5 Mei 2021

Published : 8 Mei 2021
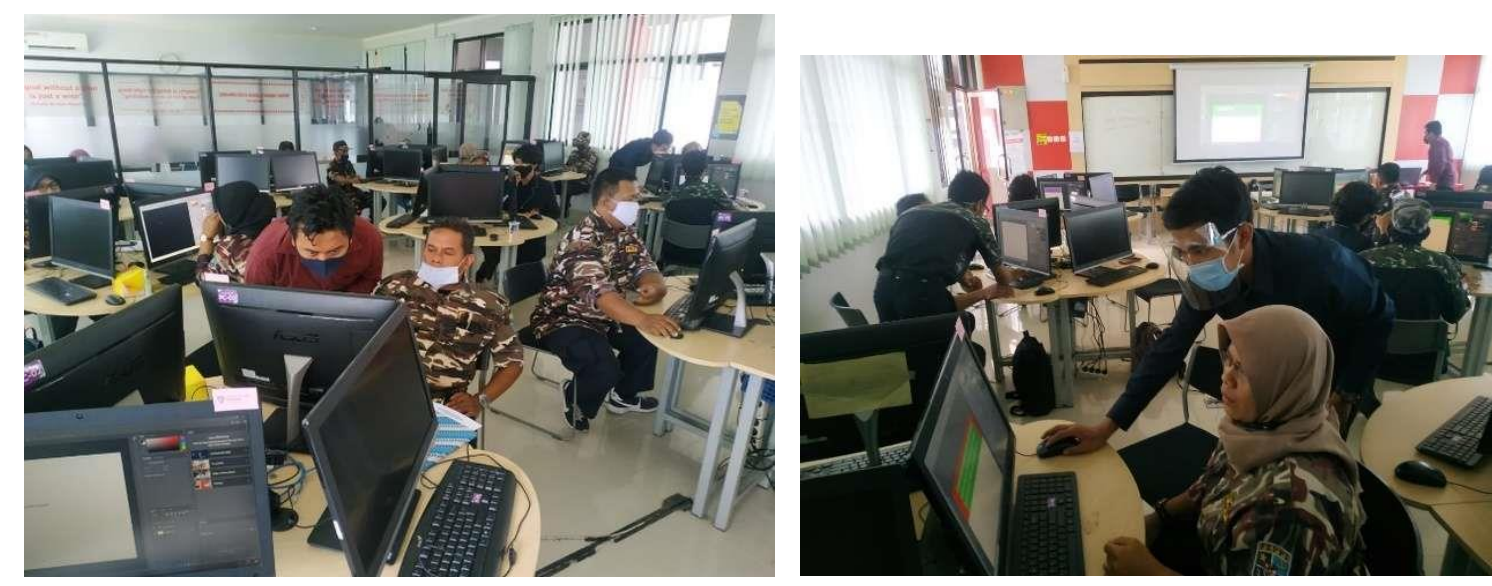

Gambar 4. Pelatihan hari kedua desain grafis menggunkan adobe photoshop

Pada peserta mengerjakan pelatihan desain grafis dengan sungguh-sungguh sehingga para peserta bisa membuat banner dan desain website dengan baik dan benar
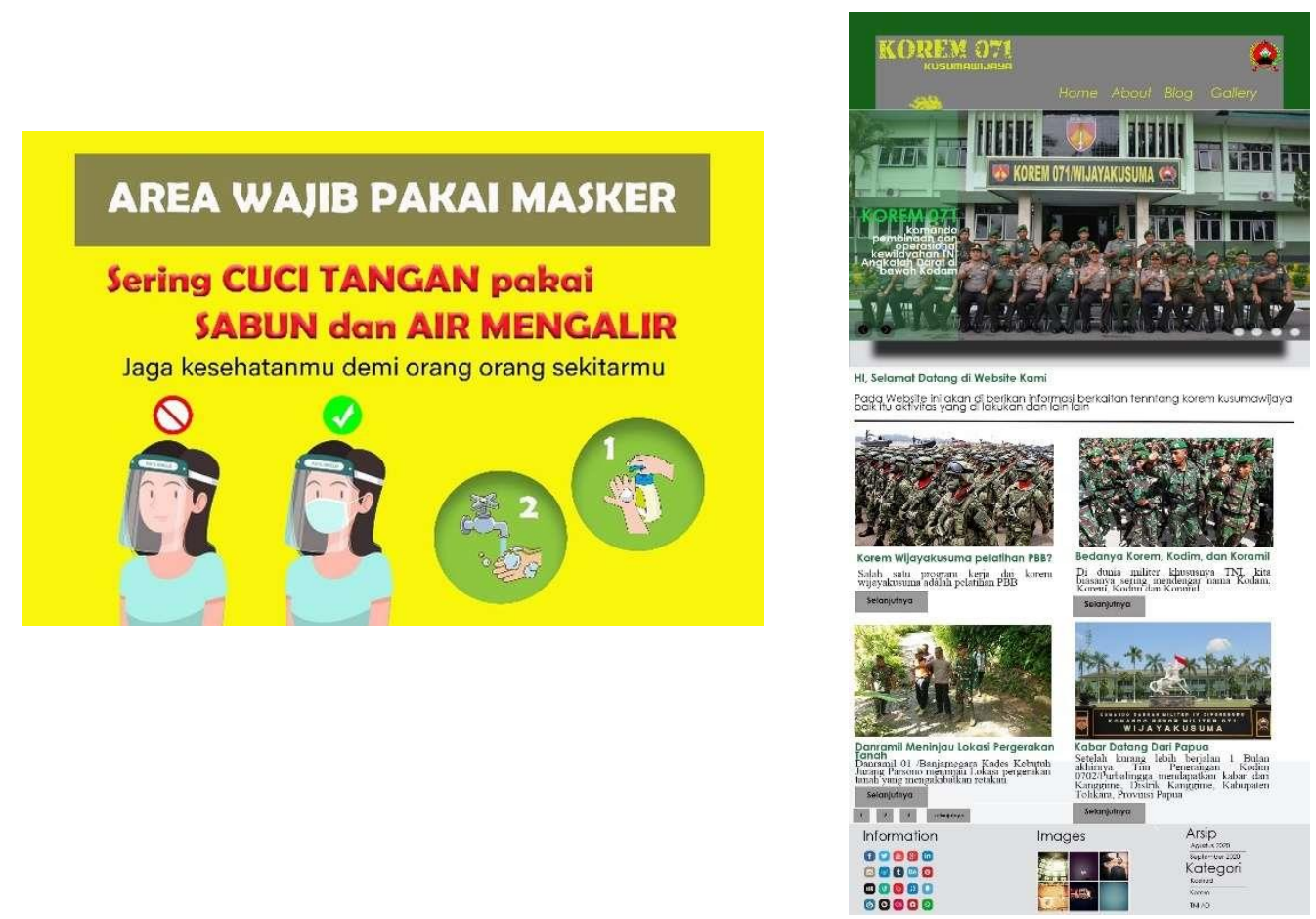

Gambar 5. Hasil desain grafis berupa banner dan desain website menggunakan adbe photoshop

Setelah melakukan pelatihan para peserta melakukan presensi dan mengisi kuisoner yang telah di beri oleh pemateri pada hari pelaksanaan pelatihan desain grafis selama dua hari 

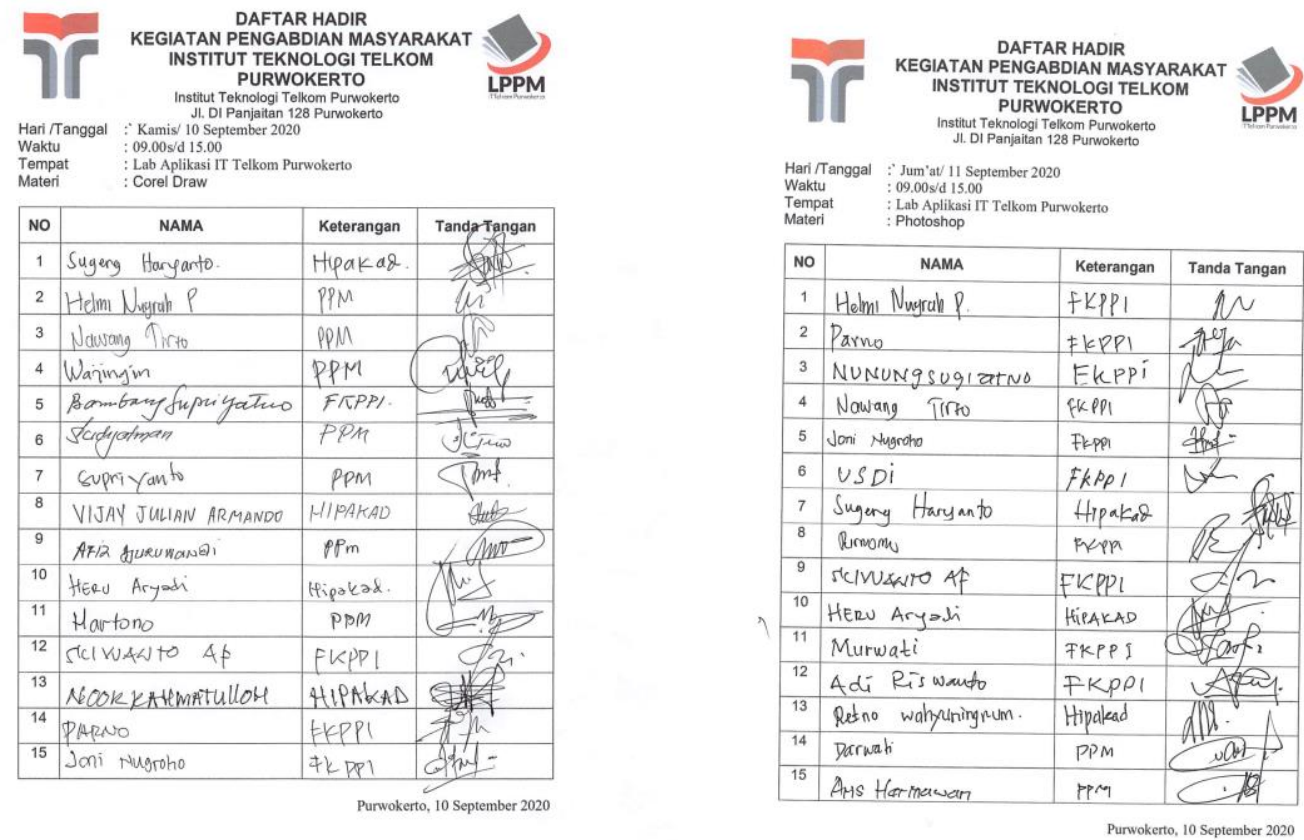

Gambar 6. Presensi Peserta

Setiap pelaksanaan pelatihan desain grafis anggota dan keluarga korem 071 wijaya kusuma di haruskan melakukan presensi setelah melaksanakan praktek desain grafis
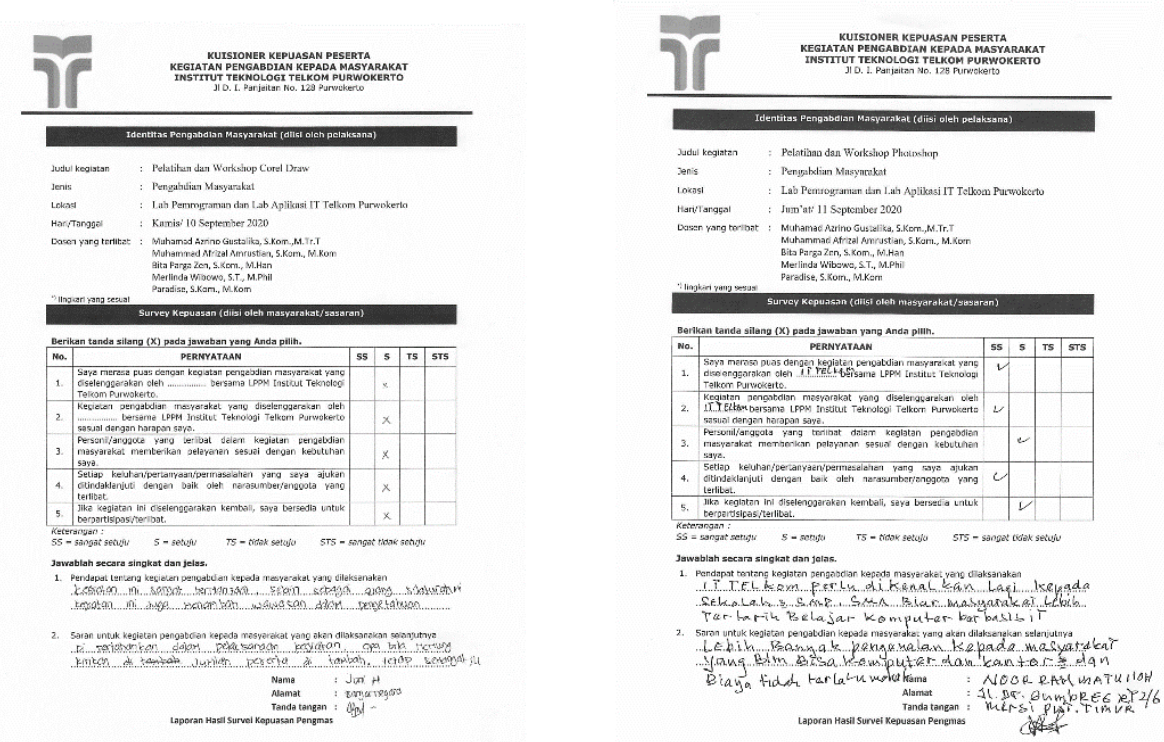

Gambar 7. Kuisoner peserta pelatihan desain grafis

Kusoner ini di berikan kepada peserta setelah peserta berhasil menyelesaikan pelatihan dan melakukan presensi pada saat hari pelatihan. Kuisoner ini bertujan untuk melihat kepuasan peserta terhadapa pelatihan desain grafis ini. Dari keseluruhan kusioner yang telah di lakukan menyatakan bahawa peserta puas terhadap kinerja pemateri dan berharap kegiatan seperti ini bisa di laksanakan kembali 
Table 1. Hasil tingkat kepuasan terhadap pelatihan desain grafis

\begin{tabular}{|c|c|c|c|c|c|c|c|c|}
\hline Hari & \multicolumn{4}{|c|}{ CorelDraw } & \multicolumn{4}{c|}{ Photoshop } \\
\hline & SS & S & TS & STS & SS & S & TS & STS \\
\hline Hari 1 & $\mathbf{2 6}$ & $\mathbf{2 4}$ & $\mathbf{0}$ & $\mathbf{0}$ & & & & \\
\hline Hari 2 & & & & & 33 & 12 & 1 & 0 \\
\hline
\end{tabular}

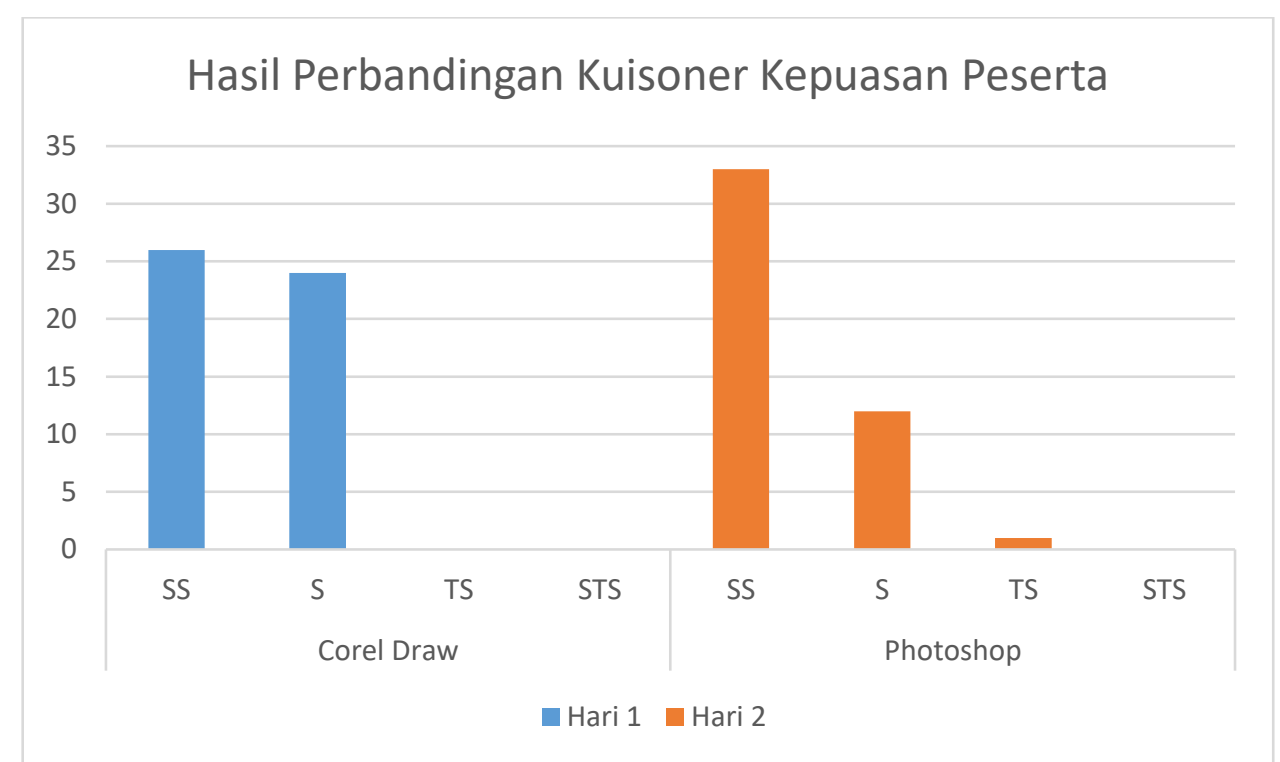

Gambar 8. Skala hasil perbandingan kepuasan peserta Hari pertam dan kedua

Pada pelatihan desain grafis kepada anggota korem 071 wijaya kusuma. Pemateri memberikan kuisoner kepada peserta di hari pelaksanaan pelatihan sebanyak sepuluh lembar. Lembar kuisoner berisi lima pertnyaan yang harus di jawab terhadap kinerja dan kepuasan para peserta. Lembar kusinoer mengggunakan skal likert dimana ada 4 nilai yang di jadikan tolak ukurnya

SS = SANGAT SETUJU

$S=$ SETUJU

TS = TIDAK SETUJU

$\mathrm{STS}=\mathrm{SANGAT}$ TIDAK SETIJU

Berdasarkan hasil likert di atas maka dapat di ketahui pada hari pertama pelatihan terdapat nilai SS atau sangat setuju sebanyak 26 suara dan nilai S atau setuju sebanyak 24 suara. Kemudian pada hari kedua pelatihan terdapat nilai SS atau sangat setuju sebanyak 33 suara, di susul oleh nilai $\mathrm{S}$ atau setuju sebanyak 12 suara dan TS atau tidak setuju sebanyak 1 suara.

\section{Kesimpulan}

Setelah diadakannya pelatihan di bidang pelatihan dan ketrampilan bagi para peserta dapat di simpulkan bahwa:

1. Anggota dan keluarga korem wijaya kusume mengikuti pelatihan dengan baik dan interaktif

2. Dengan bekal ilmu yang di dapatkan saat praktek desain grafis, peserta lebih punya pandangan untuk terjun di dunia bisnis dan membuka usaha sendiri

3. Kegiatan pengabdian ini membuat terjalainnya kerjasama antara Institut Teknologi Telkom Purowkerto dengan Korem 071 wijayakusuma 


\section{Daftar Pustaka}

Agustina, R. (2017). Pelatihan Desain Grafis Untuk Perangkat Desa Dalam Rangka Peningkatan Sdm Di Desa Ngawonggo, 2, 37-42.

Alkodri, A. A. (2020). Peningkatan Bidang Pendidikan Dan Pelatihan Keterampilan Bagi Pencari Kerja Dengan Basic Graphic Design, 1(2).

Andriyanto1, S. (2021). Pelatihan Desain Grafis Untuk Guru SMP Negeri 3 Mendo Barat Bangka, 3(1), 8-14. https://doi.org/10.35970/madani.v1i1.388

Jepriana, I. W., Ferdi, I. P., \& Putra, E. (2020). Pelatihan Microsoft Office dan Desain Grafis untuk Perangkat Desa, 3(1), 38-48.

korem071.mil.id. (2019). Welcome. Retrieved April 29, 2021, from https://www.korem071.mil.id/tentang-korem-071-wijayakusuma/

Sipayung, Y. R. (2020). Pelatihan Daring Desain Grafis Bagi Pengurus Paduan Suara Mahasiswa Satya Dharma Gita Fakultas Hukum Universitas Diponegoro, 270-274.

Yahya, F., \& Fitriyanto, S. (2020). Pelatihan Desain Grafis untuk Kelompok Pemuda Kreatif Desa Gontar Kecamtan Alas Barat Kabupaten Sumbawa, 3(2).

Yuliati, T. (2020). Pelatihan komputer grafis sebagai upaya peningkatan softskill bidang desain dan editing pada stt dumai, 26(2), 77-80. 